\title{
Participation restriction and assistance needs in people with spinal cord injuries of more than $\mathbf{4 0}$ year duration
}

\author{
Gordana Savic $^{1} \cdot$ Hans L. Frankel ${ }^{1} \cdot$ Mohamed Ali Jamous $^{1} \cdot$ Bakulesh M. Soni $^{2} \cdot$ Susan Charlifue ${ }^{3}$
}

Received: 8 February 2018 / Revised: 10 February 2018 / Accepted: 11 February 2018

(c) International Spinal Cord Society 2018

\begin{abstract}
Study design Prospective observational.

Objectives Examine changes in participation restriction and assistance needs in a sample of people with long-standing spinal cord injuries (SCIs).

Setting Two British spinal centres.

Methods The sample consisted of British ageing with SCI study participants who were seen at baseline (1990 or 1993) and in the final follow-up (2010). Outcome measures were the Craig Handicap Assessment and Reporting Technique-Short Form (CHART-SF) and interview questions about assistance needs.

Results Eighty-five Ageing study participants took part in 2010; their mean age was 67.65 years and the mean time since injury was 46.26 years. The mean CHART-SF physical independence subscore decreased from 97.44 in 1990 to 91.26 in 2010, mobility from 95.58 to 82.10 , occupation from 86.82 to 64.49 and social integration from 96.29 to 88.68 (all $p<0.05$ ). Increasing assistance needs were reported by $10.1 \%$ of participants in 1990 , by $36.6 \%$ in $2010(p<0.05)$ and by $62.4 \%$ over the entire 20-year study period. Persons requiring more assistance were older and injured longer, had a more severe SCI and lower self-reported quality of life and life satisfaction $(p<0.05)$. In the multivariate logistic regression, the strongest predictor of needing more assistance was injury severity $(p<0.05)$.

Conclusions An increase in participation restriction and in assistance needs was reported over the 20 year follow-up in persons injured more than 40 years ago. SCI severity was the main risk factor for needing more assistance. Clinical awareness of how participation changes with age may help provide timely intervention and offset declines.
\end{abstract}

\section{Introduction}

In the World Health Organization International Classification of Functioning, Disability and Health [1], 'participation restriction' replaced the term 'handicap' used previously to describe the societal perspective of functioning. Participation restrictions are described as problems an individual may experience in involvement in life situations, and their

Gordana Savic

Gordana.Savic@buckshealthcare.nhs.uk

gordanasavic@yahoo.com

1 National Spinal Injuries Centre, Stoke Mandeville Hospital, Buckinghamshire Healthcare NHS Trust, Aylesbury, UK

2 North West Regional Spinal Injuries Centre, Southport Hospital, Southport and Ormskirk NHS Trust, Southport, UK

3 Craig Hospital, Englewood, Colorado, USA presence is determined by comparing an individual's participation with that which is expected of an individual without disability in that culture or society.

People living with spinal cord injury (SCI) already experience some degree of activity limitations and participation restrictions in everyday life due to reduced functional reserves resulting from the injury and increased physical demands of living with a SCI. With advancing years, additional changes due to general ageing inevitably lead to further loss of physical functioning and independence, usually at an earlier age than in the general ageing population [2, 3]. Results from earlier rounds of the British Ageing with SCI study showed that people with tetraplegia reported a need for increased physical assistance around the age of 49 years, on average, and those with paraplegia around the age of 54 years. [4] In this and other studies, the main reasons for needing more physical assistance were noted to be pain, weakness and fatigue, with weight gain and postural changes reported as contributing factors [4-6]. 
Reduced physical independence, together with reduced mobility, occupation and socialisation, results in a decline in community integration, which can be strongly associated with person's perceived life satisfaction and quality of life (QoL) [7, 8].

The aim of this study was to establish change in levels of participation over the 20-year study period in a cohort of individuals ageing with SCI and to identify potential predictors for needing more assistance.

\section{Methods}

\section{Study design}

Prospective observational cohort study.

\section{Sample}

The sample included 85 participants of the British ageing with SCI study, who were seen at baseline in 1990 or 1993 and in the final study follow-up in 2010. The original study inclusion criteria in 1990 were as follows: traumatic SCI injury before 1971, admission to one of the participating spinal centres (Stoke Mandeville or Southport) within one year of injury, residence in the catchment area of the two participating centres and age between 15 and 55 years at the time of injury. Two hundred and ninety-three participants responded positively to invitation to participate and formed the original Ageing study sample; 282 were seen in the first study round in 1990 and another 11, who wanted to participate but could not attend in 1990, joined the study in 1993. Of the 85 participants who took part in the final 2010 round and formed the current study sample, six joined the study in 1993.

A more detailed explanation of the original sample identification procedure can be found in publications from the earlier study rounds $[3,9]$.

\section{Data collection}

Data were collected on seven occasions, in 1990, 1993, 1996, 1999, 2002, 2006 and 2010, through detailed medical records review, medical and psychosocial interview, full physical assessment and diagnostic procedures. Participants who could not travel to one of the spinal centres, but wanted to continue their participation in the study, were either seen at home or had a detailed medical and psychosocial telephone interview only.

Outcome measures analysed in this study were as follows: Craig Handicap Assessment and Reporting Technique-Short Form (CHART-SF) [10], Life Satisfaction
Index Z (LSI-Z) [11], self-reported QoL scale (0-4) and interview questions about assistance needs.

The CHART-SF [10] is a simple objective measure of the degree to which impairments and disabilities limit community participation. The CHART-SF consists of six subscales each scored on a 100-point scale, with higher scores indicating higher levels of social participation. For this study only four subscales (physical independence, mobility, occupation and social integration) were collected. Therefore, the total CHART-SF score could not be calculated.

The LSI-Z [11] is a 13-item self-reported assessment of morale and life satisfaction. Scores range from 0 to 26, with higher scores reflecting greater life satisfaction.

Self-reported QoL was assessed as part of the interview. A simple question was asked: 'How would you rate your QoL on a $0-4$ scale, where $0=$ very poor, $1=$ poor, $2=$ fair, $3=$ good, and $4=$ excellent?'

The interview also included a question: 'Has your need for assistance changed during the last 3 years?' Response options were 'No change', 'Yes, less help needed' and 'Yes, more help needed'. As there were very few 'Yes, less help needed' answers (between two and five depending on the study round), this answer was combined with the 'No change' answer and compared with 'Yes, more help needed' in the analysis. Additional questions were asked about activities requiring more assistance and reasons behind the increased need, about primary care providers and about new equipment. More than one answer was allowed for these additional questions.

Participants' SCI was classified according to the International Standards for Neurological Classification of Spinal Cord Injury [12]. The Functional Independence Measure (FIM) was used to evaluate participants' functional ability in daily activities [13]. Environmental factors were assessed using the Craig Hospital Inventory of Environmental Factors-Short Form (CHIEF-SF) [14].

\section{Data analysis}

Data analyses were performed using Statistical Package for the Social Sciences (SPSS), Version 17 (SPSS, Inc., Chicago, IL, USA).

Descriptive statistics were used for presenting the sample. Answers to open ended questions were grouped by themes and reported in percentages. Repeated-measures analysis of variance (ANOVA) and post-hoc tests with Bonferroni correction were applied to analyse change in CHART sub-scores, QoL and life satisfaction scores over time, and $\chi^{2}$ for change in assistance needs and care providers. Independent sample $t$-test and $\chi^{2}$-test were used for comparing sample subgroups. Logistic regression analysis 
was used for identifying the risk factors for needing more assistance. Statistical significance level was set at $p<0.05$.

\section{Statement of ethics}

The original 1990 study and each study follow-up had a separate ethical approval, the last one by Oxfordshire Research of Ethics Committee B Committee, reference 10/ H0605/24.

We certify that all applicable institutional and governmental regulations concerning the ethical use of human volunteers were followed during the course of this research.

\section{Results}

\section{Sample characteristics}

Of the 293 original Ageing study participants, 85 (29\% of the original sample) completed the 2010 follow-up and entered the sample, 72 participants $(24.6 \%)$ had withdrawn from the study and 136 (46.4\%) were known to have died by 2010 . Table 1 shows sample characteristics in 2010 (in bold), as well as the baseline comparison between the 2010 follow-up participants and the rest of the original Ageing study cohort. The 85 study participants who took part in the final 2010 follow-up were significantly younger at injury and at baseline than those who withdrew or died during the study $(p<0.05)$.

In the 2010 follow-up, the participants' mean age was 67.65 years (range 55-82) and the mean time since injury was 46.26 years (range $40-59$ ); $80 \%$ of the sample were male, $37.7 \%$ had tetraplegia and American Spinal Injury Association (ASIA) Impairment Scale (AIS) grade A, B or $\mathrm{C}$ lesion, $44.7 \%$ paraplegia $\mathrm{ABC}$ lesion and the remaining $17.6 \%$ AIS grade D lesion. There were no ventilator dependent cases in the sample.

\section{Participation, life satisfaction, QoL and assistance needs}

Table 2 shows change in CHART-SF sub-scores, LSI-Z, QoL and assistance needs over the 20-year study period for the 2010 follow-up participants. The mean CHART-SF physical independence, mobility, occupation and social integration subscores all decreased significantly between 1990 and 2010 follow-ups (all $p<0.05$ ). The repeatedmeasures ANOVA post-hoc tests with Bonferroni correction found the first significant change in occupation and mobility sub-scores 9 years after the study began, in physical independence after 15 years and in social integration after 20 years from the study beginning (all $p<0.05$ ). Both LSI-Z and QoL scores decreased only slightly over time,
Table 1 Sample characteristics in the 2010 follow-up (in bold) and differences between 2010 participants and the rest of the original sample at baseline

\begin{tabular}{|c|c|c|c|}
\hline & $\begin{array}{l}2010 \\
\text { Follow-up } \\
(n=85)\end{array}$ & $\begin{array}{l}2010 \text { Participants } \\
\text { at baseline }(n=85)\end{array}$ & $\begin{array}{l}\text { Non } 2010 \text { participants } \\
\text { at baseline }(n=208)\end{array}$ \\
\hline \multicolumn{4}{|c|}{ Mean (SD) years } \\
\hline $\begin{array}{l}\text { Current } \\
\text { age }\end{array}$ & $67.7(6)$ & $47.7(6.2)$ & $54.7(9.5)^{\mathrm{a}}$ \\
\hline $\begin{array}{l}\text { Age at } \\
\text { injury }\end{array}$ & $21.4(4.7)$ & $21.4(4.7)$ & $26.9(8.4)^{\mathrm{b}}$ \\
\hline $\begin{array}{l}\text { Years } \\
\text { post- } \\
\text { SCI }\end{array}$ & $46.3(4.6)$ & $26.3(4.6)$ & $27.8(8.4)$ \\
\hline \multicolumn{4}{|l|}{ Gender } \\
\hline Male & $80 \%$ & $80 \%$ & $89.7 \%$ \\
\hline Female & $20 \%$ & $20 \%$ & $10.3 \%$ \\
\hline \multicolumn{4}{|c|}{ Injury severity } \\
\hline $\begin{array}{l}\text { Tetra } \\
\text { AIS } \\
\text { ABC }\end{array}$ & $37.7 \%$ & $37.7 \%$ & $26.1 \%$ \\
\hline $\begin{array}{l}\text { Para } \\
\text { AIS } \\
\text { ABC }\end{array}$ & $44.7 \%$ & $44.7 \%$ & $54.2 \%$ \\
\hline $\begin{array}{l}\text { All AIS } \\
\text { Ds }\end{array}$ & $17.6 \%$ & $17.6 \%$ & $19.7 \%$ \\
\hline
\end{tabular}

The 2010 follow-up results are presented in bold

AIS, American Spinal Injury Association (ASIA) Impairment Scale

${ }^{\text {a }} p<0.01$ ( $t$-test) - baseline group comparison

${ }^{\mathrm{b}} p<0.05$ ( $t$-test) — baseline group comparison

and neither change reached statistical significance. For the 85 participants who completed the study, the mean total daily assistance increased from $0.64 \mathrm{~h} /$ day in 1990 to $2.18 \mathrm{~h} /$ day in 2010, with the change becoming statistically significant in the 1999 follow-up $(p<0.05)$. Increasing need for assistance over the previous 3 years was reported by $10.1 \%$ of the participants in 1990 , by $25.9 \%$ in 1999 and by $36.6 \%$ in $2010(p<0.05)$.

Over the entire 20 -year study period, $62.4 \%$ of the 2010 sample reported increasing assistance needs. In 2010, they were receiving, on average, $3.24 \mathrm{~h}$ of care a day, of which $2.24 \mathrm{~h}$ a day as paid care and $1 \mathrm{~h}$ a day as unpaid care. At the same time, those whose assistance needs have not changed during the study were receiving, on average, $0.48 \mathrm{~h}$ of care a day $(0.25$ paid and 0.23 unpaid care) $(p<$ 0.05 ). Those requiring more assistance were older and injured longer, had a more severe SCI, lower FIM, CHART-SF, LSI-Z and QoL scores, as shown in nonadjusted bivariate analysis in Table 3 (all $p<0.05$ ). They also reported higher frequency and magnitude of environmental barriers, as measured by CHIEF-SF, with differences in CHIEF-SF physical/structural and policies subscale 
Table 2 Change in selected CHART-SF sub-scores ${ }^{\mathrm{a}}$, life satisfaction, $\mathrm{QoL}^{\mathrm{b}}$ and assistance needs during the 20-year study period

\begin{tabular}{|c|c|c|c|c|c|c|c|c|}
\hline Follow-up year & 1990 & 1993 & 1996 & 1999 & 2002 & 2006 & 2010 & $p$-value* \\
\hline \multicolumn{9}{|l|}{ CHART-SF sub-score (0-100) (Mean (SD)) } \\
\hline Physical independence & $97.44(5.61)$ & $96.44(11.81)$ & $94.57(15.51)$ & $93.76(13.91)$ & $93.61(13.91)$ & $93.68(11.5)$ & $91.26(21.27)$ & 0.01 \\
\hline Mobility & $95.58(10.19)$ & $93.21(12.56)$ & $94.53(12.43)$ & $91.54(14.89)$ & $90.38(14.85)$ & $87.89(17.67)$ & $82.10(20.42)$ & $\mathbf{0 . 0 0}$ \\
\hline Occupation & $86.82(24.5)$ & $75.96(32.23)$ & $78.29(29.05)$ & $73.45(31.28)$ & $78.25(27.57)$ & $68.7(29.13)$ & $64.49(31.12)$ & 0.00 \\
\hline Social integration & $96.29(11.02)$ & $91.98(15.01)$ & $95.25(12.02)$ & $93.58(14.23)$ & $96.7(8.47)$ & $94.73(12.47)$ & $88.68(19.78)$ & 0.00 \\
\hline LSI-Z (0-26) (Mean (SD)) & $19.24(4.97)$ & $18.35(5.66)$ & $18.53(5.19)$ & $19.34(5.11)$ & $18.32(5.68)$ & $18.97(5.21)$ & $18.6(5.07)$ & 0.58 \\
\hline Self-reported QoL (0-4) (Mean (SD)) & $3.16(0.83)$ & $3.2(0.87)$ & $3.1(0.84)$ & $3.2(0.87)$ & & $3.12(0.81)$ & $2.98(0.8)$ & 0.23 \\
\hline Total daily assistance (Mean (SD) h/day) & $0.64(1.4)$ & $1.01(3.95)$ & $1.37(3.89)$ & $1.56(4.14)$ & $1.57(3.55)$ & $1.58(2.88)$ & $2.18(5.32)$ & 0.02 \\
\hline Paid assistance & $0.01(0.11)$ & 0.5 (1.99) & $0.82(3.39)$ & $0.62(1.76)$ & $1.15(3.46)$ & $0.86(2.51)$ & $1.48(4.73)$ & 0.01 \\
\hline Unpaid assistance & $0.63(1.39)$ & $0.51(2.01)$ & $0.55(1.09)$ & $0.94(3.29)$ & $0.42(0.98)$ & $0.72(1.22)$ & $0.7(2.59)$ & 0.13 \\
\hline More assistance needed (\%) & $10.1 \%$ & $11.8 \%$ & $13.1 \%$ & $25.9 \%$ & $25.6 \%$ & $25.9 \%$ & $36.6 \%$ & $\mathbf{0 . 0 0} * *$ \\
\hline
\end{tabular}

Statistically significant $p$-values are presented in bold

CHART-SF Craig Handicap Assessment and Reporting Technique - Short Form, LSI-Z Life Satisfaction Index Z, QoL Quality of Life

* Repeated-measures ANOVA

*** $\chi^{2}$-test

${ }^{\text {a }}$ CHART-SF economic self-sufficiency and cognition sub-scores were not collected in all follow-ups, so the total CHART-SF score could not be calculated

${ }^{\mathrm{b}}$ QoL scores not collected in 2002

scores reaching statistical significance (Table 3). Current age, time since injury, injury severity (measured by ASIA motor score) and gender were entered in the logistic regression analysis as independent predictors of needing more assistance. In the univariate logistic regression (Table 4a), all, except gender, were statistically significant predictors of needing more assistance, with the risk increasing by $8.5 \%$ with each additional year of age and by $12.4 \%$ with each additional year post injury, and with the risk reducing by $4.3 \%$ with each additional ASIA motor score point $(p<$ 0.05 ). When the three significant predictors from the univariate analysis were entered in the multivariate logistic regression model, the ASIA motor score remained the only statistically significant predictor of needing more assistance (Table 4b).

Activities reported as requiring more assistance were as follows: transfers $(45.5 \%$ of all named activities averaged over the entire study), personal care, which included toileting, dressing, feeding, bladder and bowel care (30.8\%), mobility (10.6\%), going out, including driving and help with shopping (8.9\%), housework (7.3\%) and $4.1 \%$ reported increased assistance in three or more activities. Transfers were the activity most frequently reported as needing more help in all follow-ups (up to $66.7 \%$ in 2006), except in the final 2010 round, when it was reported by $26.7 \%$ of the participants, whereas more assistance with personal care was reported by $46.7 \%$ in the same follow-up $(p<0.05)$. Open-ended questions about reasons for needing more assistance included pain (particularly shoulder pain), fatigue, getting older, getting weaker, loss of confidence, safety issues, time and effort required, and a few medical reasons (stroke, syrinx with ascending neurology and malignancy).

The main care provider arrangements changed significantly over time $(p<0.05)$. The proportion of hired (paid) carers went up from $5.9 \%$ in 1990 to $28.6 \%$ in 2010, whereas the proportion of relatives and friends as main care providers went down from $20.5 \%$ in 1990 to just $4.1 \%$ in 2010. The proportion of professional nurses remained the same at $6 \%$. Throughout the study, the main care providers were partners/spouses, representing $67.6 \%$ of all primary carers in 1990 and $61.2 \%$ in 2010.

Since the 1990 study round, $58 \%$ of the 2010 participants reported having changed some of their equipment and/or having acquired new equipment in the previous 3 years and in the 2010 follow-up alone this percentage was $41 \%$. Proportionally more of the participants who required more assistance also required new equipment $(50 \%)$ compared with those not requiring more assistance but acquiring new equipment $(25.8 \%), p<0.05$. The type of equipment changed over time $(p<0.05)$. In the1990 round, wheelchairs were reported by $56.5 \%$ participants, followed by seating equipment $(28.3 \%)$ and walking equipment $(8.7 \%)$. In the 2010 round, the most frequently reported new equipment was for transferring (hoists, monkey poles, grab bars, sliding sheets and sliding boards) reported by $30.3 \%$, followed by wheelchairs (lightweight and electric wheelchairs, and power-assist wheels) reported by $21.2 \%$ and seating equipment by $18.2 \%$. Other new equipment included mattresses, adjustable beds, lifts and new cars, including cars that take a person in their wheelchair. Personal 
Table 3 Differences in the 2010 follow-up between those having reported increased assistance needs during the study and the rest of the sample

\begin{tabular}{|c|c|c|c|}
\hline & $\begin{array}{l}2010 \text { Participants with increased assistance } \\
\text { needs }(n=53)\end{array}$ & $\begin{array}{l}2010 \text { Participants with unchanged assistance } \\
\text { needs }(n=32)\end{array}$ & $\begin{array}{l}p- \\
\text { Value }^{\mathrm{a}}\end{array}$ \\
\hline \multicolumn{4}{|l|}{ Mean (SD) } \\
\hline Hours of care a day & $3.24(6.49)$ & $0.48(1.31)$ & 0.022 \\
\hline Current age (years) & $68.68(5.78)$ & $65.94(6.16)$ & 0.042 \\
\hline Years post injury & $47.10(4.67)$ & $44.86(4.14)$ & 0.029 \\
\hline ASIA motor score $(0-100)$ & $45.62(15.01)$ & $65.19(27.33)$ & 0.001 \\
\hline Total FIM score $(18-126)$ & $94.13(22.61)$ & $114.62(16.67)$ & 0.024 \\
\hline CHART-SF physical independence & $87.04(25.97)$ & $98.06(5.25)$ & 0.022 \\
\hline CHART-SF mobility sub-score & $76.34(22.09)$ & $91.39(13.06)$ & 0.001 \\
\hline LSI-Z score (0-26) & $17.12(5.49)$ & $20.94(3.21)$ & 0.000 \\
\hline QoL score $(0-4)$ & $2.76(0.82)$ & $3.32(0.65)$ & 0.000 \\
\hline $\begin{array}{l}\text { CHIEF-SF physical/structural } \\
\text { subscale }(0-8)\end{array}$ & $1.10(1.31)$ & $0.50(0.48)$ & 0.016 \\
\hline CHIEF-SF policy subscale $(0-8)$ & $1.10(1.31)$ & $0.50(0.48)$ & 0.014 \\
\hline \multicolumn{4}{|l|}{ Gender } \\
\hline Male & $75.5 \%$ & $87.5 \%$ & $0.264^{\mathrm{b}}$ \\
\hline Female & $24.5 \%$ & $12.5 \%$ & \\
\hline
\end{tabular}

Statistically significant $p$-values in bold

ASIA American Spinal Injuries Association, CHART-SF Craig Handicap Assessment and Reporting Technique - Short Form, CHIEF-SF Craig Hospital Inventory of Environmental Factors-Short Form, FIM Functional Independence Measure, LSI-Z Life Satisfaction Index Z, QoL Quality of Life

${ }^{\mathrm{a}} t$-test

b $\chi^{2}$-test

Table 4 Logistic regression analyses expressed as odds ratios for needing more assistance, with $95 \%$ confidence intervals

\begin{tabular}{|c|c|c|c|c|}
\hline \multicolumn{5}{|c|}{ a. Univariate logistic regression } \\
\hline \multirow[t]{2}{*}{ Variable in the equation } & \multirow[t]{2}{*}{ Odds ratio } & \multicolumn{2}{|c|}{$\begin{array}{l}95 \% \\
\text { Confidence } \\
\text { interval }\end{array}$} & \multirow[t]{2}{*}{$p$-Value } \\
\hline & & Lower & Upper & \\
\hline Current age & 1.085 & 1.001 & 1.175 & 0.046 \\
\hline Time since injury & 1.124 & 1.010 & 1.250 & $\mathbf{0 . 0 3 3}$ \\
\hline Motor score & 0.957 & 0.931 & 0.985 & 0.002 \\
\hline Gender (male) & 0.44 & 0.130 & 1.489 & 0.187 \\
\hline \multicolumn{5}{|c|}{ b. Multivariate logistic regression } \\
\hline \multirow[t]{2}{*}{ Variable in equation } & Odds ratio & \multicolumn{2}{|c|}{$\begin{array}{l}95 \% \\
\text { Confidence } \\
\text { interval }\end{array}$} & $p$-Value \\
\hline & & Lower & Upper & \\
\hline Motor score & 0.955 & 0.927 & 0.983 & 0.002 \\
\hline Current age & 1.016 & 0.899 & 1.149 & 0.797 \\
\hline Time since injury & 1.114 & 0.950 & 1.307 & 0.184 \\
\hline
\end{tabular}

Statistically significant $p$-values in bold

contribution of more than $£ 1000$ a year towards new equipment was reported by $22 \%$ of the sample.

\section{Discussion}

The aim of this study was to analyse the change in participation restriction and in assistance needs in a sample of people ageing with SCI, and to identify potential risk factors. All study participants were injured for more than 20 years before 1990 when the study began. The sample included only the participants who had both baseline and final follow-up results in order to establish the change in the same group of individuals over the 20 year study duration.

The results showed that participation decreased over time, as measured by lower CHART-SF physical independence, mobility, occupation and social integration subscores, with changes reaching statistical significance halfway through the study or later, and for the social participation sub-score only in the final study round. More participants received more help in later study rounds, as would be expected with advancing age, especially with transfers and personal care. The reasons for needing more assistance were similar to those previously reported from this and other studies, the main ones being pain, fatigue and weakness, but also health problems, safety issues and saving time/energy [2-6, 15]. Again, as expected and as reported by others, current age, time since injury and injury 
severity were found to be the main risk factors $[2,5,16]$. In the univariate logistic regression analysis all three were significant predictors of needing more assistance. In the multivariate logistic regression, however, only the injury severity, measured by the ASIA motor score, remained a statistically significant predictor of needing more assistance, possibly due to relatively low numbers in the two subgroups.

Perceived QoL and life satisfaction showed a slight decline over time, but did not reach statistical significance. Many studies have found that life satisfaction and QoL after SCI remain relatively stable and this has been explained by shifting in priorities and by improved coping skills with age $[3,17-21]$. In the current study, both correlated well with the amount of assistance needed, being higher in those receiving less help, similar to the earlier findings from this study [8]. These subjective measures were not entered as independent predictor variables in the logistic regression model, as the direction of the causal relationship between them and the assistance needs was difficult to prove. However, it is more likely that a higher QoL resulted from being more independent than the other way round. QoL measures also correlated well with environmental factors, measured by CHIEF-SF, which was previously found in a multicentre American study [22]. The same American study identified the natural environment (measured by CHIEF-SF physical/ structural subscale), transportation and home help (measured by CHIEF-SF services/assistance subscale) as the top environmental barriers reported by individuals with SCI. Similar problems were reported in our study. A recent Australian review article identified problems with transport, inaccessibility of the natural and built environment, issues with healthcare services and rehabilitation providers, and pain as barriers to successful social and community participation [23]. All of those were reported by our participants too, but with healthcare and rehabilitation services being the smallest and the least frequent problem. This was possibly due to the fact that our sample consisted of participants followed up at two specialised spinal centres, whereas the review article included 23 studies with varied sample composition.

Increased assistance needs, reported by more than half the sample over the 20-year study period, were mainly met by additional paid assistance. Partners/spouses remained main carers for the majority of participants, but their numbers were declining slowly, as carers themselves aged. The problem of ageing carers has been highlighted before, but a satisfactory alternative has yet to be identified [24-26]. In our study the care previously provided by partners, family members and friends was mainly replaced by hired (paid) help. In England and Wales, where the study population comes from, a personal contribution towards care costs is expected from most people, except when it is considered a medical necessity. Additional equipment, often required in older age, is provided by the state if considered essential, but is often co-funded or fully funded by the individual if it is considered to be more than essential or basic. All this often exhausts individual's savings and leads to additional concerns about future financial security. It has been reported that older age combined with longer duration of SCI amplified subjects' perceptions of financial insecurity [27].

Quite understandably, people can be resistant to forfeiting any amount of independence, and often it will fall on the health and social care workers to help them accept change and additional help when it becomes necessary [7]. If more assistance is needed as people age, support systems should be in place to provide this with as little delay and disruption to the person's life as possible. In order to be able to intervene in a timely and appropriate manner, periodic reassessment of any changes in participation, activities of daily living, equipment and assistance needs should be part of regular follow-ups after SCI.

\section{Study limitations}

Relatively low participant numbers in the final follow-up may have affected some of the statistical significance results.

The assistance described in this study is the assistance actually received and may not be the same as the assistance needed. Therefore, the results probably represent the minimum, rather than the optimum, required assistance.

Longitudinal study inherent bias is that the cohort inevitably evolves to be composed of younger, and possibly healthier, participants in later follow-ups. In addition, having survived $40+$ years post SCI and having been followed at the two specialised spinal centres, this cohort probably represents the best adjusted among those with SCI, so their results may be better than the overall SCI population results would be.

\section{Conclusions}

A significant increase in participation restriction and in assistance needs was reported over the 20-year follow-up period in persons injured more than 40 years ago, with injury severity being the main risk factor for needing more assistance. At the same time, life satisfaction and perceived QoL did not decrease significantly. Awareness of how assistance needs change as individuals age with SCI is necessary among both health and social care providers, if 
timely interventions to offset declines are to be ready and available when needed.

Acknowledgements We thank all the participants who volunteered their time to take part in the study, and the staff at the collaborating spinal centres at Stoke Mandeville and Southport.

Funding Over the years, the seven study rounds were financially supported by the following funders: 1990 and 1996-National Institute on Disability and Rehabilitation Research (NIDRR), USA; 1993 - Centers for Disease Control and Prevention (CDC), USA; 1999 and 2002-Ontario Neurotrauma Foundation, Canada; 2006-Buckinghamshire Hospitals NHS Trust Charitable Spinal Fund, UK; David Tolkien Trust Fund, UK; Southport and Ormskirk Hospital Spinal Injuries Centre Endowment Fund, UK; 2010_Buckinghamshire Healthcare NHS Trust Charitable Spinal Fund, UK; and Ann Masson Legacy for Spinal Research Fund, UK.

\section{Compliance with ethical standards}

Conflict of interest The authors declare that they have no conflict of interest.

\section{References}

1. World Health Organization. The International Classification of Functioning, Disability and Health (ICF). Geneva: World Health Organization; 2001. http://www.who.int/classifications/icf/en/.

2. Charlifue S, Jha A, Lammertse D. Aging with spinal cord injury. Phys Med Rehabil Clin N Am. 2010;21:383-402.

3. Savic G, Charlifue S, Glass C, Soni BM, Gerhart KA, Jamous MA. British ageing with SCI study: changes in physical and psychosocial outcomes over time. Top Spinal Cord Inj Rehabil. 2010;15:41-53.

4. Gerhart KA, Bergstrom E, Charlifue SW, Menter RR, Whiteneck GG. Long-term spinal cord injury: functional changes over time. Arch Phys Med Rehabil. 1993;74:1030-4.

5. Liem NR, McColl MA, King W, Smith KM. Aging with a spinal cord injury: Factors associated with the need for more help with activities. Arch Phys Med Rehabil. 2004;85:1567-77.

6. Thompson L. Functional changes in persons aging with spinal cord injury. Assist Technol. 1999;11:123-9.

7. Savic G, Charlifue S. Aging with spinal cord injury. In: Chhabra HS(ed.) ISCoS textbook on comprehensive management of spinal cord injuries. New Delhi: Wolters Kluwer. 2015;906-17.

8. Charlifue S, Gerhart K. Community integration in spinal cord injury of long duration. NeuroRehabilitation. 2004;19:91-101.

9. Whiteneck GG, Charlifue SW, Frankel HL, Fraser MH, Gardner BP, Gerhart MS. Mortality, morbidity, and psychosocial outcomes of persons spinal cord injured more than 20 years. Paraplegia. 1992;30:617-30.

10. Whiteneck GG, Charlifue SW, Gerhart KA, Overholser JD, Richardson GN. Quantifying handicap: a new measure of long-term rehabilitation outcomes. Arch Phys Med Rehabil. 1992;73:519-26.
11. Wood V, Wylie ML, Sheafor B. An analysis of a short self-report measure of life satisfaction: correlation with rater judgments. J Gerontol. 1969;24:465-9.

12. American Spinal Injury Association. International Standards for Neurological Classification of Spinal Cord Injury. Atlanta, GA, USA: American Spinal Injury Association; 2015. Revised 2011, updated 2015

13. Keith RA, Granger CV, Hamilton BB, Sherwin FS. The functional independence measure: a new tool for rehabilitation. Adv Clin Rehabil. 1987;1:6-18.

14. Whiteneck GG, Harrison-Felix CL, Mellick DC, Brooks CA, Charlifue SB, Gerhart KA. Quantifying environmental factors: a measure of physical, attitudinal, service, productivity, and policy barriers. Arch Phys Med Rehabil. 2004;85:1324-35.

15. Lundström U, Wahman K, Seiger A, Gray DB, Isaksson G, Lilja M. Participation in activities and secondary health complications among persons aging with traumatic spinal cord injury. Spinal Cord. 2017;55:367-72.

16. Noreau L, Fougeyrollas P. Long-term consequences of spinal cord injury on social participation: the occurrence of handicap situations. Disabil Rehabil. 2000;22:170-80.

17. Krause JS, Coker JL. Aging after spinal cord injury: a 30-year longitudinal study. J Spinal Cord Med. 2006;29:371-6.

18. Krause JS, Newman JC, Clark JM, Dunn M. The natural course of spinal cord injury: changes over 40 years among those with exceptional survival. Spinal Cord. 2017;55:502-8.

19. Pollard C, Kennedy P. A longitudinal analysis of emotional impact, coping strategies and post-traumatic psychological growth following spinal cord injury: a 10-year review. Br J Health Psychol. 2007;12:347-62.

20. Whiteneck G, Forchheimer M, Krause JS. Quality of life and health in the last years after spinal cord injury. Top Spinal Cord Inj Rehabil. 2007;12:77-90.

21. Sakakibara BM, Hitzig SL, Miller WC, Eng JJ, SCIRE Research Team. An evidence-based review on the influence of aging with a spinal cord injury on subjective quality of life. Spinal Cord. 2012;50:570-8.

22. Whiteneck G, Meade MA, Dijkers M, Tate DG, Bushnik T, Forchheimer MB. Environmental factors and their role in participation and life satisfaction after spinal cord injury. Arch Phys Med Rehabil. 2004;85:1793-803.

23. Barclay L, McDonald R, Lentin P. Social and community participation following spinal cord injury: a critical review. Int $\mathrm{J}$ Rehabil Res. 2015;38:1-19.

24. Rodakowski J, Skidmore ER, Rogers JC, Schulz R. Does social support impact depression in caregivers of adults ageing with spinal cord injuries? Clin Rehabil. 2013;27:565-75.

25. Weitzenkamp DA, Gerhart KA, Charlifue SW, Whiteneck GG, Savic G. Spouses of spinal cord injury survivors: the added impact of caregiving. Arch Phys Med Rehabil. 1997;78:822-7.

26. Baker A, Barker S, Sampson A, Martin C. Caregiver outcomes and interventions: a systematic scoping review of the traumatic brain injury and spinal cord injury literature. Clin Rehabil. 2017;31:45-60.

27. Pentland W, McColl MA, Rosenthal C. The effect of aging and duration of disability on long term health outcomes following spinal cord injury. Paraplegia. 1995;33:367-73. 